\title{
Crítica à Parte Geral do Anteprojeto de Código Civil.
}

\author{
Antonio Junqueira de Azevedo \\ Assistente doutor na regência da cadeira de \\ Teoria Geral de Direito Civil da Faculdade \\ de Direito da Universidade de São Paulo.
}

\section{Introdução.}

O presente artigo é de crítica ao Anteprojeto de Código Civil apresentado pela Comissão Elaboradora e Revisora do Código Civil, ao Ministro da Justiça, em 23 de maio de 1972.

Cingir-nos-emos à Parte Geral, cuja elaboração coube ao professor José Carlos Moreira Alves, jurista que prima pela precisão de conceitos e clareza das classificações doutrinárias.

Quanto à estrutura da Parte Geral, tendo sido mantida, falta nela, a nosso ver, um livro. A existência de um livro, após o tratamento das pessoas, bens e fatos jurídicos, eliminaria muitas das contradições e deficiências existentes no Código de 1916 e agora repetidas. Queremos nos referir a um livro sobre os äireitos subjetivos. Essa, pois, a nossa principal crítica à Parte Geral do Anteprojeto: falta, nela, o livro sobre os direitos subjetivos. Em conseqüência, os preceitos sobre este assunto estão espalhados, e de forma incompleta, pelos outros livros, com prejuízo da segurança das relações jurídicas e da lógica que deve predominar justamente na Parte Geral, reflexo das mais altas sistematizações científicas, cúpula normativa de todo o Direito. 


\section{Desenvolvimento da crítica fundamental.}

Depois do tratamento das pessoas, como sujeitos de direito, dos bens, como objetos de direito, e dos fatos jurídicos, como causas da aquisição, modificação ou extinção dos direitos, nada mais natural que se tratasse dos próprios direitos. Dir-se-á que é exatamente deles que trata a Parte Especial do Código; ora, não é bem assim. Em primeiro lugar, nossa sugestão é para que haja um livro sobre os direitos subjetivos em geral, e não, evidentemente sobre os direitos subjetivos em espécie. Em segundo lugar, é preciso deixar claro que a própria Parte Especial não trata somente dos direitos subjetivos; muitos e muitos de seus preceitos dizem respeito a fatos jurídicos (fatos jurídicos especiais) e, apesar disso, há, na Parte Geral, o livro Dos Fatos jurídicos.

Aliás, a esse respeito já dizia o grande TeIxeIra DE FreITAS (Introdução à Consolidação das Leis Civis, Garnier Livreiro - Editor, $3 .^{2}$ edição, Rio, 1896, p. cxIx) : “a parte especial de um Código Civil descreve os direitos por suas diferenças, regula as relações jurídicas como engendradas, o que supõe os fatos, que lhes tem dado origem, e regula também alguns desses fatos". Justamente porque os fatos estão ligados aos direitos, o ilustre jurista brasileiro, por ocasião da feitura da Consolidação, se opunha à colocação dos fatos jurídicos na Parte Geral, "in verbis": "alguns escritores adicionam este terceiro elemento sob denominação de factos, factos jurídicos, actos jurídicos, de que tratam também na parte preliminar das matérias de Direito Civil. Não nos conformamos com esse método". Agora, veja o leitor o seguinte: mais tarde, aquele, que é reconhecidamente um dos maiores juristas brasileiros do século passado, não teve dúvidas em mudar de idéia e, por ocasião da elaboração do Esboço, colocou, na Parte Geral, uma seção, a Terceira, com o nome Dos Factos, e ainda acrescen- 
tou em nota (nota ao art. 431): "Esta Seção 3. a, que trata dos fatos, um dos elementos dos direitos regulados no Código Civil, não estava em meu primeiro plano, como se pode ver na Consolidação das Leis Civis - Introdução, pp. 106, 107 e 108. Hoje, ao contrário, estou convencido de que sem esse método será impossível expor com verdade a síntese das relações de Direito Privado..." E mais adiante: "É verdade, como se disse na citada Introdução (à Consolidação), que a parte especial de um Código Civil regula as relações jurídicas como engendradas, o que supõe os fatos que lhes tem dado origem. E bastará regular somente essas relações engendradas? Não, por certo, e tanto assim que ali também reconheci que se regula, como sempre se tem regulado, alguns dos fatos que produzem essas relações, quais são os contratos e testamentos, dispondo-se sobre as suas condições essenciais, seus vícios e suas formas, embora (minhas palavras) algumas dessas disposições sejam suscetíveis de uma aplicação comum. Pois bem: essas disposições suscetíveis de uma aplicação comum e que em todos os Códigos tem sido particularizadas à matéria dos contratos e testamentos são as que agora, em seu caráter próprio de onicomprensão, tenho coligido nesta Seção $3 .^{\mathrm{a}}$ da Parte Geral do Projeto".

Ora bem, o mesmo argumento, de que se serviu Teixeira DE Freitas para mudar de idéia sobre os fatos jurídicos, é que, agora, deveria servir à douta Comissão para colocar, na Parte Geral, o livro sobre os direitos subjetivos. Isto é, como, hoje, em doutrina, há, sabidamente, proposições susceptíveis de aplicação comum a essas situações jurídicas, que convencionalmente se chamam direitos subjetivos, o futuro Código Civil, a fim de se manter no mesmo plano da Ciência Jurídica, deveria receber, transformadas em normas, aquelas proposições.

Antes de passarmos a demonstrar as contradições e deficiências que, com essa providência, seriam eliminadas, lembramos que praticamente todas as mais recentes obras 
de Direito Civil tratam dos direitos subjetivos em sua parte preliminar. (Nas citações, que seguem, a ordem obedecida é a cronológica pela data de publicação da primeira edição). Alguns autores, por seguirem de perto o Código Civil, preferem versar o assunto em poucas palavras, comparando-o ao direito objetivo e sem lhe dedicar capitulo especial; é o que acontece com Washington de Barros MonTEIRo (Curso de Direito Civil, 1958) e Silvio Rodrigues (Direito Civil, 1962). Outros dedicam ao direito subjetivo todo um capítulo, examinando sua conceituação, com as várias teorias a respeito, seus elementos e sua classificação, assim: João Franzen de Lima (Curso de Direito Civil Brasieiro, 1952), Orlando Gomes (Introdução ao Direito Civil, 1957), Cato Mario da Silva Pereira (Instituições de Direito Civil, 1961), Vandick L. da Nóbrega (Compendio de Direito Civil, 1971), e Antônio Chaves (Lições de Direito Civil, 1972). Outros ainda vão mais longe. Paulo Dourado de GusMÃo (Elementos de Direito Civil, 1969) trata do direito subjetivo em extenso capítulo e, no restante da exposição, realça sobremaneira a sua conceituação. Rubens Limongi França (Manual de Direito Civil, 1966) centraliza toda a segunda parte da exposição sobre as noções gerais de Direito Civil, na idéia de direito subjetivo, denominando-a mesmo de Doutrina Geral dos Direitos Subjetivos. Finalmente, há quem dedique ao direito subjetivo em gerál, não propriamente um capítulo, mas vários, apresentando-o ao final da Teoria Geral do Direito Civil; é o que faz Pontes de Miranda no seu monumental Tratado de Direito Privado; aí, o direito subjetivo está examinado no chamado "plano de eficácia", que vem após o plano de existência (onde se examinam as pessoas, os bens e os fatos jurídicos) e do plano de validade (validade, nulidade e anulabilidade). Realmente, é esta a posição certa; direito subjetivo é efeito de fato jurídico (plano de eficácia), devendo, assim, seu estudo, bem como sua posição na lei, vir após o fato jurídico, que lhe dá origem. 
A ordem, que nos parece melhor, para a Parte Geral do Código Civil (precedida das regras sobre o direito objetivo), é, pois: em primeiro lugar, o sujeito de direito; depois, o objeto de direito; ambos são elementos jurídicos (elemento pessoal e elemento real), adotada a palavra "elemento" em seu sentido lexical, como diz CARNELUTTI (Teoria Generale del Diritto, Soc. Ed. del "Foro Italiano", Roma, 1951, $3 .^{\text {a }}$ ed. pp. 11), ou seja, "principia omnium rerum, ex quibus reliqua omnia componuntur et in quibus resolvuntur"; em terceiro lugar, o fato jurídico, isto é, o fato do mundo real, que coincide com a hipótese prevista na lei e sobre o qual a lei incide, atribuindo-lhe efeitos; através do fato jurídico, os elementos do direito (estática jurídica) põem-se em movimento (dinâmica jurídica). Em quarto e último lugar, deveria haver as regras aplicáveis aos direitos subjetivos em geral, como efeitos de fatos jurídicos, completando-se, assim, o "lucidus ordo" da Parte Geral.

Poder-se-ia dizer que, como os direitos subjetivos não são os únicos ef eitos dos fatos jurídicos, o quarto livro, que estamos sugerindo, não deveria ter seu nome, e sim, o mais amplo de "efeitos jurídicos". $E$ idéia que não nos repugna mas então, também o livro Das Pessoas deveria ter seu título mudado para Dos Sujeitos de Direito, já que pessoa é conceito menos amplo que sujeito de direito, havendo sujeitos de direitos, como o nascituro, o espólio, o condomínio em edificações, as sociedades de fato, etc., que, por lei, não são pessoas. O mesmo se diga ainda sobre o livro Dos Bens, em face da noção de objeto de direito.

Por outro lado, o fato de haver um livro sobre o direito subjetivo, não envolve, em princípio, nenhuma tomada de posição doutrinária sobre as várias teorias a respeito. Um livro, na lei, sobre o direito subjetivo, não traz sequer, embora isto possa parecer uma afirmação tola, a conseqüência de que, cientificamente, o direito subjetivo exista. Realmente, o "Papa" das teorias negativistas, HANs KeLSEN, não 
se limita a negar o direito subjetivo; nega também a pessoa jurídica, apesar de esta estar consagrada, há séculos, nas diversas legislações. Com muito de verdade, o citado autor vê, em ambos (pessoa jurídica e direito subjetivo), apenas, fórmulas destinadas a expressar a realidade jurídica, que dentro de uma teoria pura do direito, podem perfeitamente ser dispensadas. Aliás, a célebre "superação do dualismo de Direito em sentido objetivo e Direito em sentido subjetivo", pela recondução do segundo ao primeiro (Teoria Pura do Direito, trad. de J. Baptista Machado, Armenio Amado, Editor, Sucessor, Coimbra, 1962, 2. ${ }^{\text {a }}$ edição, pg. 361), vem, exatamente, depois de tratar da pessoa jurídica e dentro do capítulo sobre o sujeito de direito. Basta isso para verificamos que, sob o ponto de vista de Kelsen, a admissão, pela lei, de um conceito, ainda que de forma expressa, não tolhe, nem impede, à Ciência do Direito, uma negação doutrinária do mesmo conceito (à ciência, pertence a esfera do "verdadeiro" e, à norma jurídica, a esfera do váliclo).

\section{Sugestões para o livro “Dos Direitos Subjetivos".}

O livro Dos Direitos Subjetivos deveria conter, pelo menos, três títulos: Dos Limites e das Diferentes Classes dos Direitos, Da Aquisição, Perda e Transferência dos Direitos e Da Ação, da Prescrição e da Decadência.

\section{Limites dos direitos.}

O primeiro título abriria com a regra sobre os limites da existência dos direitos, assim formulada: "os direitos somente existem nos limites de seus fins econômicos e sociais". Segue dai que o titular de um direito somente pode exercê-lo dentro desses limites; fora disso, qualquer ato, ainda que, aparentemente, seja exercício de direito, já é ato contra direito e, se causar dano, será ato ilícito. $O$ 
Anteprojeto consagra essa idéia, mas, em lugar errado e de forma defeituosa. Realmente, no art. 187, define o ato ilícito como sendo, em síntese, o ato que viola direito e causa dano; depois, no art. 188, diz que o titular de um direito, que, ao exercê-lo, excede "os limites impostos pelo fim econômico ou social, pela boa-fé ou pelos bons costumes", também comete ato ilícito. Ora, ou o titular de um direito tinha direito a agir como agiu, ou não tinha; se tinha, o ato é lícito e nenhum desses dois artigos se aplica; se não tinha, $o$ ato é ilícito e se aplica somente o art. 187 (o ato violou direito e causou dano). $\mathrm{O}$ art. 188 , portanto, sobre o dito exercício excessivo de direito, não se aplica nunca, e, numa lógica jurídica rigorosa, é inútil. Percebe-se que a intensão da Comissão é ajudar a jurisprudência, fornecendo-lhe uma muleta (a do chamado "abuso de direito") para certos casos limítrofes entre o ilícito e o lícito, mas melhor seria que se evitasse a lamentável contradição que o art. 188 encerra em seu bojo. Afinal, não é possível que ocorra o que diz esse artigo, ou seja, que alguém, ao exercer um direito, cometa simultâneamente um ato ilícito; se comete ato ilícito, é porque direito não tinha. "Nemo damnum facit, nisi qui id fecit, quod jus non habet" (D. 50, 17, 151, Paulus, LXIV, ad Edictum). A regra, a ser formulada portanto, há de ser sobre os limites dos direitos. "Os direitos somente existem nos limites de seus fins econômicos e sociais".

\section{Direitos registráveis e não registráveis.}

Viria, depois, a grande classificação dos direitos. $\mathrm{O}$ Anteprojeto, na determinação de quais sejam os bens móveis e imóveis (arts. 78 e 83) mantém a mesma insuperável contradição existente no Código atual e consistente em enumerar, ao lado de objetos de direito, os próprios direitos. São considerados imóveis o solo, tudo que se incorpora ao solo (plantações e construções, por exemplo) e materiais de 
construção provisoriamente separados do prédio (arts. 78 e 80); tudo isso, evidentemente, é objeto de direito; são coisas sobre as quais incide, em geral, o direito de propriedade de alguém. É ilógico enumerar, depois, ao lado desses bens, também, por exemplo, o próprio direito de propriedade sobre os imóveis (art. 79, I). A mesma confusão ocorre a respeito dos móveis; tanto são bens móveis os semoventes ("bens suscetíveis de movimento próprio", art. 81), quanto os direitos sobre eles (art. 82, II).

A contradição não escapou, nem à lei atual, nem ao Anteprojeto, pois ambos, depois de determinarem, quanto aos objetos, quais os que são móveis e quais os que são imóveis, acrescentam quanto aos direitos, que estes serão móveis ou imóveis, "para os efeitos legais". Esse "remendo", porém, não elimina a contradição, pois, evidentemente, também os objetos (e, não apenas, os direitos) serão móveis ou imóveis para os efeitos legais (seria inconcebivel que assim não fôsse).

$\mathrm{Na}$ verdade, o que o legislador brasileiro está fazendo é repetir, sobre móveis e imóveis, o mesmo, exatamente o mesmo, êrro da classificação romana das coisas em corpóreas (os objetos palpáveis) e incorpóreas (os direitos). Essa classificação é sempre citada e sempre criticada, justamente por confundir o objeto de direito com o próprio direito, ou seja, por colocar, lado a lado, entidades heterogêneas (Confiram-se, o Esboço, de Teixeira de Freitas, nota ao art. 317; as Instituições, de Roberto DE RugGiero, trad. do Dr. Ary dos Santos, Edição Saraiva, São Paulo, $1971,3 .^{a}$ edição, p. 263, do Vol. II; e Direito Romano de José Carlos Moreira Alves, Forense, Rio, 1971, 3. ${ }^{\text {a }}$ edição, p. 155, do Vol. I). Este último, a quem, embora com independência de espírito, citamos com admiração, diz: "a classificação das coisas em corpóreas e incorpóreas tem sido muito criticada (daí, não ter sido, em geral, admitida nos Códigos modernos) porquanto se a coisa é objeto de direito, como classificá-la em coisas e direitos? Os direitos não podem ser capitulados en. 
tre as coisas que são seu objeto". No entanto, é isto que está no Anteprojeto sobre os bens móveis e imóveis.

A solução que damos é a seguinte: a classificação dos bens em móveis e imóveis, fundamental na ordem jurídica atual, tira sua importância, não, do fato de que há coisas com mobilidade e coisas sem mobilidade, como poderia parecer à primeira vista, e sim, de que há direitos, que são mais importantes perante a ordem econômica e social, e direitos que o são menos, fazendo o legislador coincidir os primeiros com as coisas que não tem mobilidade e os segundos, com as que tem mobilidade. No fundo, o que realmente é fundamental para a ordem jurídica é que há “ $d i$ reitos classe-A" $\mathrm{e}$ "direitos classe- $B$ ". Os primeiros, pela sua grande importância na ordem econômica e social, exigem atos solenes de transferência e aquisição, quando objeto de atos "inter-vivos"; a segurança das relações jurídicas impõe, para esses direitos, qualquer que seja o ordenamento jurídico, uma série de formalidades (para nós, atualmente, o registro; no Direito Romano clássico, a "mancipatio" e a "in jure cessio"). Já para os "direitos classe-B", em virtude de sua menor importância, os negócios "inter-vivos" feitos sobre eles são mais simples; basta a tradição, ou o título, para a sua transferência e aquisição; as exigências de economia para as partes e as do próprio comércio se sobrepõem às de segurança, impondo menor número de formalidades.

Nesse sentido, isto é, entendidos como direitos "classe-A" e "classe-B", a atual classificação dos bens em móveis e imóveis é tão universal, quanto a romana, em "mancipi" e "nec mancipi". Tomada, porém, ao pé da letra, leva a absurdos; na legislação vigente, por exemplo, os rios e as quedas d'água, figuras clássicas para expressar a mudança constante das coisas e da própria vida, são imóveis (art. 43, I, do Código Civil e art. 145 do Código de Águas); o gado de uma fazenda, desde que "intencionalmente empregado na exploração industrial, aformoseamento 
ou comodidade" é, enquanto vivo, bem imóvel, mas, depois de morto, passa, justamente, a ser móvel. É quase um surrealismo jurídico, de que o Anteprojeto procurou fugir, sem, porém, o conseguir totalmente.

A solução está em, no livro Dos Bens, classificar os objetos de direito em móveis e imóveis, sem se referir a direitos. Depois, no livro Dos Direitos Subjetivos, aí sim, classificar os direitos em duas classes, de acôrdo com sua importância na ordem econômica e social; os mais importantes poderiam ser ditos "direitos registráveis" e os menos importantes, “direitos não registráveis". Essa passaria a ser a classificação fundamental dos direitos para a ordem jurídica nacional.

Isto evitaria as contradições acima apontadas (confusão entre direito e objeto de direito; inclusão de coisas óbviamente móveis entre os móveis, e vice-versa), e ainda traria as seguintes enormes vantagens, resultantes da maleabilidade da nova categoria: a) os direitos reais sobre determinados bens móveis, que tem, atualmente, grande importância, passariam a se submeter, sem maiores problemas, a regime jurídico compatível com a situação; queremos nos referir aos direitos sobre automóveis, caminhões, aviões, navios, motocicletas, etc. Seriam todos "direitos registráveis", exigindo o registro para a sua efetiva transferência; b) determinados direitos reais sobre bens imóveis, que, por sua vez, deixaram de ter, atualmente, grande importância, passariam a se reger por regras mais simples; assim, os direitos reais resultantes de promessas de compra-e-venda sobre imóveis de valor inferior a cem vezes o maior salário mínimo vigente no país (ou seja, $\operatorname{Cr} \$$ $31.200,00)$, e respectivas cessões, portanto, compromissos sobre pequenos apartamentos, casas populares, lotes não muito grandes e respectivas cessões não precisariam de qualquer registro, podendo se provar a titularidade do direito real pela posse, somada ao título ou ao simples pa- 
gamento das prestações. (Evidentemente a aquisição da propriedade teria que ser registrada).

A "summa divisio" dos direitos seria, pois, direitos registráveis (direitos reais sobre imóveis em geral, e ações que os asseguram, direitos reais sobre móveis automotores e respectivas ações, e direito à sucessão aberta) $e$ direitos não registráveis (direitos reais sobre móveis em geral e ações correspondentes, direitos reais resultantes de promessa de compra-e-venda sobre imóveis de valor inferior a cem vezes o maior salário mínimo vigente no país, suas cessões, e respectivas ações, e direitos pessoais de caráter patrimınial e as ações que os asseguram). Os primeiros seriam os direitos que teriam como fato jurídico de aquisição, quando transferidos por atos inter-vivos, o registro, e os segundos os que teriam como modo de aquisição, nas mesmas hipóteses, a tradição ou o títuló. Essa providência colocaria a lei em posição de paridade com a realidade, pois, quanto aos direitos citados na letra "a" supra, já é esta, na mentalidade geral, a situação atual; e também quanto a letra "b", é preciso sentir o povo mais simples que promete comprar ("compra"), a prestações, seu lote de terreno, compra-e-venda e, até mesmo, muitas vezes, deixando as parcelas mensais, raramente registrando a promessa de compra-e-venda e, até mesmo, muitas vêzes, deixando as duas vias do contrato nas mãos do promitente vendedor (loteador ou incorporador), ou perdendo a sua via de contrato, ou ainda sem contrato absolutamente.

Haveria muito a dizer sobre o assunto; por exemplo, são questões a estudar: a) a inclusão, desde logo, entre os direitos registráveis, das ações nominativas, da chamada propriedade industrial, dos direitos autorais de conteúdo patrimonial e do direito ao nome com caráter econômico; b) a extensão, aos direitos registráveis, de outras aplicações hoje ligadas aos bens imóveis, assim, a exigência de outorga uxória (parecendo-nos, porém, que a melhor solução, pelo menos por enquanto, é a de manter a situação atual, 
isto é, tais exigências somente seriam feitas para os atos sobre imóveis, excetuados, naturalmente, os casos de direito reais sobre imóveis não registráveis). Entretanto, o presente artigo já se estende e há que tratar, rapidamente, das outras disposições que o livro sobre os direitos subjetivos poderia conter. Acrescentamos, apenas, que, considerando o relêvo cada vez maior que os bens móveis adquirem na economia moderna, a manutenção, no Anteprojeto, da classificação dos bens em móveis e imóveis, com o caráter confuso de divisão simultânea de objetos de direito e de direitos, corre o risco de se transformar em "verdadeiro fóssil no sistema jurídico", para empregarmos as expressivas palavras do prof. José Carlos Moreira Alves (obra citada, pg. 164) falando sobre a classificação das coisas em "mancipi" e "nec mancipi", ainda existentes na época de Justiniano.

\section{Complexos de direitos.}

Poderiam vir, ainda no mesmo título, em seguida à grande classificação dos direitos, outras classificações (direitos principais e acessórios, absolutos e relativos, etc.) e, pelo menos, uma norma sobre os complexos de direitos, as "universitates juris". Realmente, a universalidade de direito é "complexo de relações jurídicas", como diz o art. 90, do Anteprojeto; ora, porque é "complexo de relações jurídicas", e não, conjunto de objetos, o lugar certo da regra não pode ser no livro Dos Bens. Ainda, aqui, portanto, a separação rigorosa entre objeto de direito e direito (no caso, complexo de direitos) se impõe, devendo trazer o deslocamento da regra do art. 90 para a "sedes materiae" correta; a leitura atenta do parágrafo único, do art. 89 , e do artigo 90 mostram claramente o que acabamos de dizer. Em segundo lugar, a regra sobre a universalidade de direito não pode ficar apenas na sua definição; salvo melhor juízo, parece-nos que não basta dizer teóricamente que a univer- 
salidade de direito é constituida pelo "complexo de relações jurídicas de uma pessoa, dotada de valor econômico". O que há aí é apenas uma definição (aliás, mais apropriada a patrimônio, do que a todas as universalidades de direito; confira-se Clóvis Beviláqua, Com. ao G. Civil, art. 57). A norma deveria ser completada pelo princípio dito da subrogação real no universal, segundo o qual, ao indivíduo, fica subrogado o respectivo valor, e vice-versa.

\section{Transferência de direitos.}

No segundo título do livro Dos direitos Subjetivos, deveriam vir as regras sobre suas vicissitudes ( $D a$ Aquisição, Perda e Transferência dos Direitos).

O Código atual traz regras sobre a aquisição e a perda dos direitos (arts. 74 a 80), algumas das quais, aperfeiçoadas, poderiam ser aproveitadas, ao invés de serem puramente eliminadas como aconteceu no Anteprojeto. Nesse título, ficariam também as regras, já referidas, sobre a aquisição, por atos inter-vivos, dos direitos registráveis e não registráveis. Indispensável, porém, nos parece um artigo sobre a transferência dos direitos; a regra poderia ser: "ninguém transfere a outrem mais direitos do que tem" ("nemo plus iuris ad alium transferre potest, quam ipse haberet" - D. 50,17,54 - Ulpianus XLVI ad edictum). A única exceção, colocada em parágrafo, seria para os casos em que o transmitente, embora não seja o titular do direito, tenha, por fôrça da lei ou negócio jurídico, o poder de disposição (por exemplo, o Poder Judiciário, ao alienar os bens penhorados; o credor pignoratício, ao promover venda amigável; o exequente nos casos de execução extrajudicial; etc.).

Sobre o mesmo assunto (aquisição e transferência de direitos), para eliminar dúvidas e resolver questões que até hoje não encontraram solução definitiva na doutrina e 
jurisprudência brasileiras, poder-se-ia acrescentar artigo que dissesse que, embora o título de transferência do direito, fornecido por quem, para tanto, não tinha poderes, não seja eficaz para realização da transferência, pode, entretanto, somado a outras circunstâncias (onerosidade do negócio, boa-fé e diligência normal) e através do fato jurídico peculiar, servir à aquisição por outrem.

A regra poderia ser assim formulada: "Embora o título de transferência, quando passado por quem do direito não tinha o poder de disposição, não seja eficaz para realizar a transferência, pode, somado à onerosidade do negócio jurídico, à boa-fé e à diligência normal do adquirente, levar este, através do fato jurídico peculiar, à aquisição do direito". De fato, uma coisa é a transferência por alguém, e outra, a aquisição por outrem; o título de transferência pode não ser eficaz para o fim exato para o qual surgiu, mas, ainda assim, ajudar a compor a hipótese legal de aquisição do direito (ele "entra no suporte fático" de aquisição do direito). Em outras palavras, se o título não é eficaz para a transferência, não haverá aquisição derivada do direito; isto, entretanto, não impede que haja aquisição originária, ou seja, que o título, juntamente com onerosidade do negócio, mais a boa-fé e a diligência normal do adquirente, levem, através do fato jurídico de aquisição, à aquisição. Uma norma desse tipo resolverá, de vez, o tormentoso problema das vendas "a non domino". Se A aliena a $B$ imóvel, que não lhe pertence, $B$ não o adquire; mas, se $B$ obtiver o registro em seu nome e, depois, vender o imóvel a $\mathrm{C}$, que examinou o registro, comprou de boa-fé e, por sua vez, também obteve o registro em seu nome, acaso $\mathrm{C}$ não se torna proprietário? A doutrina e a jurisprudência hoje hesitam na resposta; a norma sugerida resolve o problema: C será o proprietário por aquisição originária; ao título, que, por si, não bastaria, terá somado o registro (fato jurídico de aquisição, no caso, modo de aquisição), mais a onerosidade do negócio, a boa-fé e a dili- 
gência normal. A aquisição do direito se dará sem que tenha havido transferência originária, dita "prescription acquisitive momentanée" pelos franceses, por se assemelhar a um usucapião imediato; cf. Pontes de Miranda, Tratado de Direito Privado, § 592.

\section{Ação de direito material.}

Finalmente, o último título do livro Dos Direitos Subjetivos deveria conter as normas sobre a ação de direitò material, a prescrição e a decadência. A regra sobre a ação poderia ser: "A todo direito, quando violado, corresponde direito de ação que o assegura", fórmula que não se atasta muito do art. 75, do atual Código Civil, e que tem a virtude de não deixar direito algum desprotegido; a "ação" aí salvaguardada é um novo direito dado ao prejudicado (direito material a agir, direito de arrastar o réu a juízo). Considerando-se que o direito de ação é autônomo em relação ao direito subjetivo, havendo mesmo inúmeros casos de direito de ação sem que haja, antes dele, qualquer direito subjetivo (por exemplo, nas ações de contestação de paternidade, nas ações de nulidade de negócios jurídicos, etc.), o artigo proposto precisa ser bem entendido; ele, de nenhuma forma, interferirá nessas situações de direịto de ação, sem direito subjetivo anterior; seu alcance é somente o de atribuir esse outro direito, que é o direito de ação, ao titular de um direito subjetivo violado; isto, evidentemente, não impede que a mesma atribuição seja feita também em outras circunstâncias. Por outro lado, o próprio titular do direito subjetivo violado pode vir a perder seu direito de ação (por exemplo, por prescrição ou perempção), o que demonstra, muito bem a autonomia do direito de ação em relação ao direito subjetivo, e, com a qual, repetimos, o artigo proposto não interfere. Visa ele apenas, evitar que, sob qualquer pretexto, um direito isubjetivo 
violado fique sem proteção, de forma a não poder seu titular agir (ou reagir) processualmente.

Terminariam o livro ora sugerido os artigos sobre prescrição e decadência, que, no Anteprojeto, se encontram no livro Dos Fatos Jurídicos. Acreditamos que essa nova colocação, até mesmo sob o aspecto estético, seria melhor, de vez que especialmente a prescrição, como forma de extinção da ação, dá uma idéia de fim, com a qual se encerraria, tal e qual acontece no Código de 1916 (mas não no Anteprojeto, toda a Parte Geral).

\section{Conclusão}

Aliás, concluindo, podemos åizer, dentro da mesma ordem de idéias, que a sugestão, que acabamos de fazer para a inclusão de um livro, na Parte Geral, sobre os direitos subjetivos, traria a esta maior harmonia. O livro Dos Fatos Jurídicos, não ficaria tão grande quanto está no Anteprojeto, em desproporção com os Das Pessoas e Dos Bens. Os assuntos estariam mais bem distribuidos e o próprio pensamento humano não ficaria interrompido, já que, depois de ter examinado as pessoas, os bens e os fatos jurídicos, que põem as pessoas em relação umas com as outras, atribuindo-lhes direitos, não sentiria ele a falta do tratamento destes, como se o curso do raciocínio tivesse sido cortado antes do fim. 